\title{
Investigation of cellular responses upon interaction with silver nanoparticles
}

\author{
This article was published in the following Dove Press journal: \\ International Journal of Nanomedicine \\ 27 August 2015 \\ Number of times this article has been viewed
}

\author{
Ramesh Subbiah ${ }^{1,2}$ \\ Seong Beom Jeon ${ }^{3,4}$ \\ Kwideok Park ${ }^{1,2}$ \\ Sang Jung $A h^{4,5}$ \\ Kyusik Yun ${ }^{3}$
}

'Center for Biomaterials, Korea Institute of Science and Technology, Seoul, ${ }^{2}$ Department of Biomedical Engineering, Korea University of Science and Technology, Daejon, ${ }^{3}$ Department of Bionanotechnology, Gachon University, Gyeonggi-do, ${ }^{4}$ Centre for Advanced Instrumentation, Korea Research Institute of Standard and Science, ${ }^{5}$ Major of Nano Science, Korea University of Science and Technology, Daejeon, Republic of Korea
Correspondence: Sang Jung Ahn

Centre for Advanced Instrumentation, Korea Research Institute of Standard and Science, Daejeon 34II3, Republic of Korea

Tel +82428685609

Email sjahn@kriss.re.kr

Kyusik Yun

Department of Bionanotechnology,

Gachon University, Gyeonggi-do I3120,

Republic of Korea

Tel +82 3l 7508753

Email ykyusik@gachon.ac.kr
Abstract: In order for nanoparticles (NPs) to be applied in the biomedical field, a thorough investigation of their interactions with biological systems is required. Although this is a growing area of research, there is a paucity of comprehensive data in cell-based studies. To address this, we analyzed the physicomechanical responses of human alveolar epithelial cells (A549), mouse fibroblasts (NIH3T3), and human bone marrow stromal cells (HS-5), following their interaction with silver nanoparticles (AgNPs). When compared with kanamycin, AgNPs exhibited moderate antibacterial activity. Cell viability ranged from $\leq 80 \%$ at a high AgNPs dose $(40 \mu \mathrm{g} / \mathrm{mL})$ to $>95 \%$ at a low dose $(10 \mu \mathrm{g} / \mathrm{mL})$. We also used atomic force microscopycoupled force spectroscopy to evaluate the biophysical and biomechanical properties of cells. This revealed that AgNPs treatment increased the surface roughness $(P<0.001)$ and stiffness $(P<0.001)$ of cells. Certain cellular changes are likely due to interaction of the AgNPs with the cell surface. The degree to which cellular morphology was altered directly proportional to the level of AgNP-induced cytotoxicity. Together, these data suggest that atomic force microscopy can be used as a potential tool to develop a biomechanics-based biomarker for the evaluation of NP-dependent cytotoxicity and cytopathology.

Keywords: AFM, roughness, nanoindentation, biomarker, cytotoxicity, biomechanics

\section{Introduction}

Nanoparticles (NPs) are smart materials with a size range of 1-100 nm; they have attractive properties including their unique size, shape, stability, desirable physicochemical properties, and their predisposition to functionalization. ${ }^{1-3}$ NPs are finding applications in various research fields including renewable energy, environment, electronics, photonics, mechanics, industrial, textiles, food, agriculture, health care, and biomedical sciences. ${ }^{4}$ In addition to polymeric NPs, ${ }^{3}$ inorganic NPs such as gold $(\mathrm{Au})$, silver ( $\mathrm{Ag})$, silica ( $\mathrm{Si}$ ), and iron ( $\mathrm{Fe}$ ) have been extensively investigated for use in nanomedicine as antimicrobials, imaging agents, targeted drug delivery systems, cancer therapeutics, implants, and biomarkers. ${ }^{46}$ Despite their huge biomedical potential, many NPs interact unfavorably with culture media, substrates, or other individual species such as biomolecules, rendering them intrinsically toxic. This limits their widespread usage in a clinical setting. ${ }^{7,8}$ Size, surface area, charge, solubility, and $\mathrm{pH}$ are the main characteristics associated with the detrimental toxicity of NPs. ${ }^{8-10}$ The combination of extremely small dimensions and increased surface area enhances the cellular interaction and uptake of NPs. This engenders toxic effects that include morphological alteration (cell membrane rupture), disruption of intracellular metabolic pathways, and generation of reactive oxygen species and subsequent oxidative stress. ${ }^{11}$ In light of this, one approach to increase the efficacy of NPs while reducing their side effects is to modulate their uptake and/or release from endosomes. This process is submit your manuscript | www.dovepress.com

Dovepress

http://dx.doi.org//0.2147/IJN.S88508
International Journal of Nanomedicine 2015:10 (Special Issue on diverse applications in Nano-Theranostics) 191-201 |9 | (c) (i) (5) 2015 Subbiah et al. This work is published by Dove Medical Press Limited, and licensed under Creative Commons Attribution - Non Commercial (unported, v3.0) License. The full terms of the License are available at http://creativecommons.org/licenses/by-nd/3.0/. Non-commercial uses of the work are permitted without any further permisson how to request permission may be found at: http://www.dovepress.com/permissions.php 
highly dependent on the ability of NPs to breach the cell membrane, as well as on the kinetics of uptake, concentration, size, surface area, and charge of NPs. ${ }^{9}$ The forces that drive nano and biological systems could explore their ability of sensing, adhesion, and targeted protein binding by appropriate integration of cytotoxicity. ${ }^{12,13}$ Thus, evaluating their mechanism of action at the nanoscale level, as well as the interactions that occur at the interface of biological systems and NPs will facilitate their successful transition into multiple biomedical applications. ${ }^{10}$ While several studies have reported the mechanisms that underlie NP-dependent cytotoxicity, ${ }^{14,15}$ the understanding of the biophysical and biomechanical properties of cells after NPs treatment seems to be limited. ${ }^{16}$ Furthermore, the molecular interactions at the bio-nano scale remain uncharacterized.

Atomic force microscopy (AFM) has emerged as a powerful tool to investigate the properties of biological samples such as live cells and extracellular matrix. ${ }^{12,17,18}$ Recent reports underscore the important role of AFM in biomedical studies including the mechanical properties of stem cells involved in lineage specification, ${ }^{19,20}$ mechanics-based cancer diagnosis, ${ }^{21}$ investigation of bacterial resistance to antibiotics, ${ }^{22}$ detection of aging cartilage and osteoarthritis, ${ }^{23}$ stem cell differentiation by matrix elasticity, ${ }^{24}$ molecular-molecular interaction, ${ }^{25}$ and protein-cell adhesion. ${ }^{26}$ Hence, the application of AFM to the study of interfaces has begun to reveal the interaction between cells and NPs at picoNewton $(\mathrm{pN})$ sensitivity and high accuracy. In addition to providing insight into interface interactions at the molecular level, which will accelerate the development of therapeutic NPs, we suggest that AFM studies can also be exploited in order to develop NP-based biomarkers.

Investigation of morphology (average cell height), biophysical (roughness, adhesion force $[\mathrm{AdF}]$, and attractive force $[\mathrm{AtF}]$ ), and biomechanical (stiffness) properties of various mammalian cells before and after NPs treatment is lacking. Hence, an attempt made in this study to unravel the effect of NPs on physical/mechanical properties of cells with respect to cytotoxicity. For this regard, we synthesized silver NPs (AgNPs) via a reduction reaction by using a syringe pump-assisted ultrasonication method. The cytotoxicity of these NPs in mouse fibroblast cells (NIH3T3), human bone marrow stromal cells (HS-5), and human alveolar epithelial cells (A549) was tested. Cells were imaged using bio-AFM, and force spectra (FS) analysis was carried out in order to observe biophysical and biomechanical changes induced by the AgNPs. The toxicity of materials was linked to changes in cellular morphology and cellular biophysical and biomechanical properties, including roughness and stiffness.
The antibacterial activity of the AgNPs was comparable to that achieved by the standard antibiotic (kanamycin). Together, these data show that changes in the biophysical and biomechanical properties of cells in response to AgNPs are valuable predictors of cytotoxicity and should be further explored for their utility as biomarkers.

\section{Materials and methods AgNPs synthesis and characterization}

The reducing agent sodium borohydride $\left(6 \mathrm{mM} \mathrm{NaBH}{ }_{4}\right.$; Aldrich) was added drop-wise to the precursor of $1 \mathrm{mM}$ silver nitrate $\left(\mathrm{AgNO}_{3}\right.$; SigmaUltra) by using a syringe pump at $10 \mathrm{~mL} / \mathrm{h}$ in the presence of ultrasonication (VC505, Sonics) to ensure complete reduction. An instant color change was observed, and the reaction was repeated using excess $\mathrm{NaBH}_{4}$ for 6 hours with continuous stirring. The probe ultrasonication parameters were optimized as pulse on-off (5-10 seconds), probe temperature $\left(60^{\circ} \mathrm{C}\right)$, and amplitude $(30 \%)$. Impurities and excess reagents were removed by several washes with deionized water (with a resistance of $>18 \mathrm{M} \Omega$, purified by a Milli-Q system from Millipore Co., Milford, MA, USA) and AgNPs were collected by centrifugation, dried in an oven at $40^{\circ} \mathrm{C}$, and stored for further use. The morphology and topography of the AgNPs were determined by using high-resolution transmission electron microscopy (JEOL-1010), field emission scanning electron microscopy (FE-SEM; JEOL 7500F), and Bio-AFM (Nanowizard II, JPK), respectively. The sample was air-dried and sputtercoated with platinum before examination by FE-SEM. AFM studies for materials were carried out in air contact mode. Elemental, structural, and optical analyses were performed by using energy dispersive X-ray analysis (S-4700 Hitachi) and X-ray powder diffraction (XRD; StoeSTADI-P2), and UV visible spectroscopy (Optizen 3220), respectively. Size and surface charge of the AgNPs (optimized concentration of $0.1 \mathrm{mg} / \mathrm{mL}$ in Dulbecco's Modified Eagle's Medium [DMEM]) were evaluated using a Malvern Zetasizer Nano ZS series.

\section{Bacterial strains and antimicrobial study}

The antimicrobial activities of AgNPs were tested using the disc-diffusion assay method as previously described ${ }^{27}$ by using pathogenic bacterial strains; Gram-positive strains Enterococcus faecalis (KCCM 13807), Staphylococcus aureus (KCTC 1916), Staphylococcus epidermidis (KCTC 1971), and Bacillus subtilis (KCTC 1021), and Escherichia coli (KCTC 1682), Salmonella typhimurium (KCCM 40253), and Salmonella enterica (KACC 10763). Briefly, bacterial strains grown in Luria-Bertani (LB) broth were 
swabbed on the surface of Mueller-Hinton agar plates. Filter paper discs (Fisher Scientific, Pittsburgh, PA, USA) saturated with $30 \mu \mathrm{g}$ of the AgNPs (Test) and Kanamycin (standard) were added to the plates. Following incubation at $37^{\circ} \mathrm{C}$ overnight, the diameters of the clear zones around the discs, called "zones of inhibition", were recorded. Minimum inhibitory concentrations (MICs; defined as the lowest concentration of the compound that inhibited $90 \%$ of the growth when compared with that of the control) were determined by using the micro dilution method. LB medium was used as the diluent for bacterial strains. Inocula were prepared using bacteria from overnight cultures in sterile LB media. Two-fold dilutions of samples and standards were prepared in 96-well plates. Approximately $10^{7}$ colonyforming unit $/ \mathrm{mL}$ cells were inoculated into a final volume of $0.2 \mathrm{~mL}$ per well and incubated at $35^{\circ} \mathrm{C}$ for 24 hours. After incubation, the microwell plates were read at $590 \mathrm{~nm}$ by using an ELISA plate reader (Thermoscientific Multiscan spectrum) prior to and after incubation to determine the MIC values.

\section{Cell culture and cytotoxicity assays}

In vitro cytotoxicity assays were performed as previously described. ${ }^{12}$ A549 cells (Korea Cell Line Bank, Seoul, South Korea), NIH3T3 cells, and human bone marrow stromal cells (HS-5, ATCC, Manassas, VA, USA) were used. For the CCK- 8 assay, on day $1,1.0 \times 10^{4}$ cells were placed in each well of a 96 -well plate in $100 \mu \mathrm{L}$ of RPMI 1640 media (A549), DMEM, (NIH3T3 and HS-5 cells) containing 10\% fetal bovine serum (purchased from GIBCO, Rockwille, MD, USA) and cultured for 24 hours at $37^{\circ} \mathrm{C}$. The final concentrations of materials ranged from $40 \mu \mathrm{g} / \mathrm{mL}$ to 1.25 $\mu \mathrm{g} / \mathrm{mL}$, and cytotoxicity was evaluated after treatment in triplicate by using a colorimetric CCK-8 assay kit (Dojindo Molecular Technologies Inc., Gaithersburg, MD, USA). The CCK-8 solution after incubation was collected and centrifuged at $15,000 \times g$ and only the AgNP-free supernatant was used for the measurement because AgNPs might exhibit strong interference in the assay. The procedure was followed according to the manufacturer's protocols and the plates were read at $450 \mathrm{~nm}$ by using an ELISA plate reader. Relative viability was calculated by setting the values of empty wells to $0 \%$ and those with untreated cells to $100 \%$. For the glutathione (GSH) assay, cells were exposed to materials $(1.25-40 \mu \mathrm{g} / \mathrm{mL})$ for 24 hours, followed by collection of $1 \times 10^{6}$ cells by centrifugation at $1,000 \times g$ for 10 minutes at $4^{\circ} \mathrm{C}$, and homogenization in $1 \mathrm{~mL}$ of $50 \mathrm{mM}$ MES buffer. Lysates were centrifuged at $10,000 \times g$ for 15 minutes at $4^{\circ} \mathrm{C}$. Following this, lysates were deproteinized with $5 \%$ sulfosalicylic acid, and analyzed for total GSH using the Detect $\mathrm{X}^{\circledR} \mathrm{GSH}$ colorimetric detection kit, as per the manufacturer's instructions. GSH concentration is obtained by subtracting the oxidized GSH (GSSG) level from the total GSH. For evaluation of lipid peroxidation, a thiobarbituric acid-reactive substance assay was used, which detects malondialdehyde (MDA). Cells in exponential growth phase were seeded into a six-well plate and incubated for 24 hours. The cells were exposed to materials $(1.25-40 \mu \mathrm{g} / \mathrm{mL})$ for 24 hours, then $1 \times 10^{6}$ cells were harvested in $200 \mu \mathrm{L}$ icecold phosphate-buffered saline and sonicated in order to completely disrupt the cells. Cell lysate $(20 \mu \mathrm{L})$ was collected for a Bradford protein assay, and an additional 100 $\mu \mathrm{L}$ of cell lysate was placed into a new $1.5 \mathrm{~mL}$ tube. Then, $200 \mu \mathrm{L}$ ice-cold $10 \%$ trichloroacetic acid was added to each sample and incubated for 5 minutes on ice. The tube was centrifuged for 5 minutes at $12,000 \times g$ and clarified supernatant was placed in a new tube. MDA was measured by QuantiChrom ${ }^{\mathrm{TM}}$ TBARS Kit, following the manufacturer's instructions, and the results were calculated as $\mu \mathrm{M}$ MDA. The institutional ethical committee of the Korea Institute of Science and Technology approved the project.

\section{Biophysics and biomechanics by AFM-FS}

AFM-FS was performed as previously described. ${ }^{12,28}$ Briefly, cells were cultured on Thermanox coverslips placed in a 12 -well culture plate at a density of $2 \times 10^{5}$ cells per well in respective media at $37^{\circ} \mathrm{C}$ in a humidified atmosphere containing $5 \% \mathrm{CO}_{2}$. Cells were allowed to attach overnight and before the addition of fresh media. AgNPs solutions $(40 \mu \mathrm{g} / \mathrm{mL})$ were then added to the wells; after a 4-hour incubation, the medium was replenished and cells were grown for a further 24 hours. After removal of medium, cells were washed with phosphate-buffered saline buffer and used for AFM studies. The changes in biophysical properties (cell height, AdF, and roughness) as well as biomechanics (stiffness) were analyzed using a Bio-AFM mounted on an inverted optical microscope (Nikon). AFM studies were carried out in liquid contact mode by using 1 M HEPES buffer ( $\mathrm{pH}$ 7.4). The scan size was adjusted to $10 \times 10 \mu \mathrm{m}, 50 \times 50 \mu \mathrm{m}$, or $100 \times 100 \mu \mathrm{m}$ in order to accommodate typical surface features while maintaining a high resolution. CONT-S sphere probes $(400 \mathrm{~nm}$ radius; NanoWorld Services GmbH, Erlangen, Germany) with $0.4 \mathrm{~N} / \mathrm{m}$ force constant were employed for nano-indentation analysis, and all data were acquired at standard culture condition $\left(37^{\circ} \mathrm{C}, 5 \% \mathrm{CO}_{2}\right)$. For stiffness measurements, indentation was carried out immediately after scanning the area of interest using the same probe. The ramp size in this study was $1 \mu \mathrm{m}$, and the loading speed was $1 \mu \mathrm{m} / \mathrm{s}$. A series 
of indentation forces $(0.5-10 \mathrm{nN})$ was performed, and the average stiffness of each sample was calculated from $10 \%$ to $20 \%$ of the indentation depth out of measured cell height to prevent cell surface defects and hertz model limitation. For mechanical analysis, tip-sample separation curves were used, and stiffness was subsequently determined using JPK data processing software. The Poisson ratio of the cells was considered to be 0.5 . In addition, force-distance measurements were performed between the probe-bare substrate, probe-blank cells, and probe-AgNP-treated cells by advancing the tip to contact the cell interface. The force was acquired as a function of the tip-sample distance $(\mu \mathrm{m})$. After the tip came into contact with the cell, the adhesion forces $(\mathrm{nN})$ during the extension and retraction of the vertical deflection of tip from the substrate surface were analyzed. For all the force-distance curve analyses, the sensitivity and spring constant of the cantilever were kept constant at $25 \mathrm{~nm} / \mathrm{V}$ and $0.040 \mathrm{~N} / \mathrm{m}$, respectively. For surface roughness analysis, the data obtained from the Bio-AFM height scale images were used to calculate the roughness of control and AgNP-treated cells. Using JPK image processing software, the cell surface was estimated through the application of a mean filter to the raw data. Roughness value was measured over the particular cell surface areas with a fixed size of $40 \times 40 \mu \mathrm{m}^{2}$ (for bare and AgNP-treated cells). In addition, for the correlation study, the stiffness and roughness of cells were plotted as scattered graph against cells viability before and after treatment with AgNPs; and the correlation coefficient value $\left(R^{2}\right)$ was calculated.

\section{Statistics}

Comparisons between paired groups were performed using independent Student's $t$-tests. For all analyses, the probability of a type I error $\leq 0.05$ was considered as statistically significant. Each test was repeated on five separate samples.

\section{Results and discussion AgNPs synthesis}

AgNPs were synthesized via a reduction reaction using a syringe pump-assisted ultrasonication method. Ultrasonics minimized the ionic concentration gradient and enhanced mass transport at the solid sphere-liquid interface, thereby producing homogeneous sphere-shaped NPs. The morphology of the newly synthesized AgNPs was characterized. Figure $1 \mathrm{~A}-\mathrm{C}$ shows the AFM, high-resolution transmission electron microscopy, and FE-SEM images of the sphere-shaped AgNPs, respectively. The corresponding high magnification images are also given in lower panel of
Figure 1A-C. All imaging modalities yielded highly similar results. The surface roughness of the AgNPs was moderately smooth, with a root mean square (RMS) roughness of $3.44 \mathrm{~nm}$ (Figure 1E). The average size of the AgNPs was 19.5 $\pm 7.7 \mathrm{~nm}$; the size distribution is shown in Figure $1 \mathrm{G}$ and indicates near-homogeneity NP preparations with negligible aggregation. The surface charge ( $\zeta$ potential) of the AgNPs in the culture media was $-18 \pm 0.6 \mathrm{mV}$. Structural confirmation was analyzed using UV spectroscopy, EDX, and XRD. AgNPs were associated with strong surface plasmon resonance absorption curves between $380 \mathrm{~nm}$ and $440 \mathrm{~nm}$ (Figure 1D). In addition, the XRD (Figure $1 \mathrm{~F}$ ) patterns of AgNPs showed relatively sharp peaks at $\sim 37.68^{\circ}, \sim 44.02^{\circ}, \sim 64.24^{\circ}$, and $\sim 81.46^{\circ}$, induced by crystalline planes of silver that were assigned as (111), (200), (220), and (222), respectively. Elemental analysis revealed a $99.27 \%$ silver content, indicating an impurity-free AgNPs synthesis (Figure 1H). The AFM-FS study yielded an AdF of $2.1 \pm 0.3 \mathrm{nN}$ and stiffness of $46.7 \pm 5.8 \mathrm{MPa}$ for AgNPs.

\section{Antimicrobial activity and cytotoxicity}

Figure $2 \mathrm{~A}$ shows the mean diameter of growth inhibition (zones of inhibition) of both Gram-positive and -negative bacteria. The results demonstrate that the growth of inhibition of AgNPs is as comparable to the standard antibiotic (kanamycin). Figure 2B shows MIC values of AgNPs and kanamycin tested against both Gram-positive and Gramnegative bacteria. Maximum growth inhibition was observed for S. aureus, S. epidermidis, and S. typhimurium. The MICs for these strains ranged from $32 \mu \mathrm{g} / \mathrm{mL}$ to $64 \mu \mathrm{g} / \mathrm{mL}$, which were equal to the MICs for kanamycin. Several researchers reported the concentration-dependent antimicrobial activity of AgNPs by the following mechanism..$^{29,30}$ Increased surface area of AgNPs causes a significant increase in penetration and accumulation in the bacterial cytoplasmic membrane that increases the potency to release silver ions. In addition, AgNPs generate free radicals that bind to biological molecules in the cellular membrane containing sulfur, oxygen, or nitrogen; this causes damage. ${ }^{31}$ The toxicity assays (CCK-8, GSH, and lipid peroxidation) were carried out using HS-5, NIH3T3, and A549 cells treated with the AgNPs. Serially diluted samples (40, 20, 10, 5, 2.5, and $1.25 \mu \mathrm{g} / \mathrm{mL}$ of AgNPs, respectively) were used for the CCK- 8 study. Figure $2 \mathrm{C}$ shows that viability was relatively unaffected at concentrations up to $10 \mu \mathrm{g} / \mathrm{mL}$, whereas considerable changes in the cell viability started to appear at $20 \mu \mathrm{g} / \mathrm{mL}$. The $20 \%$ reduction in viability (ie, $80 \%$ viability compared with control) was noticed with $40 \mu \mathrm{g} / \mathrm{mL}$ of AgNPs; this was the case for all cell types. We hypothesize 

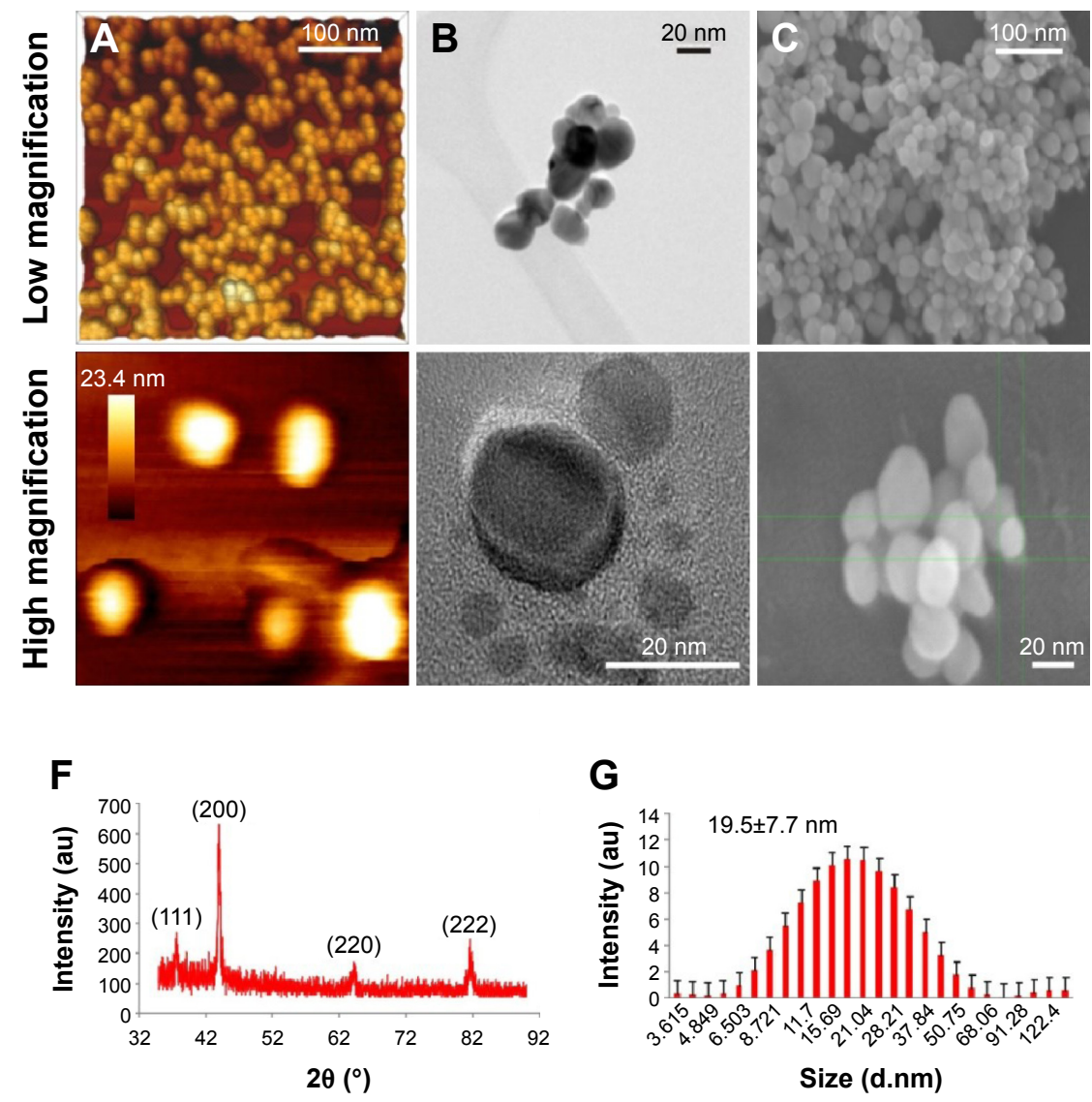

E
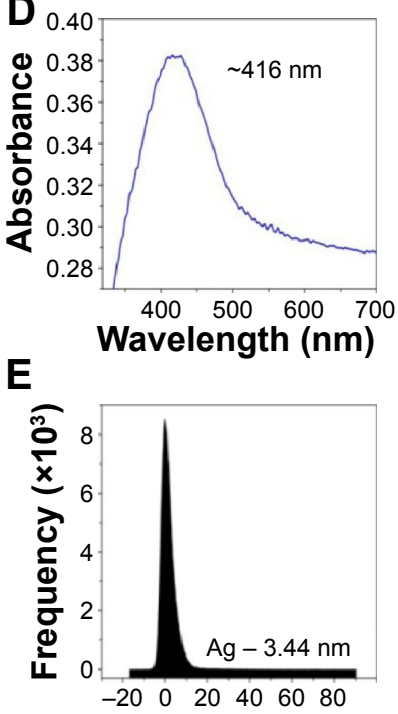

Histogram (nm)

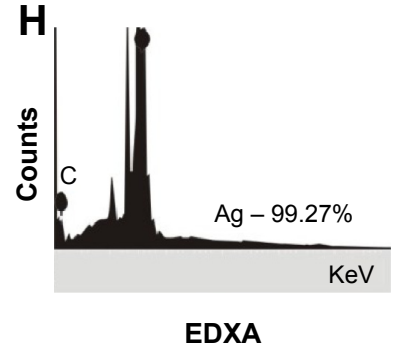

\begin{tabular}{|c|c|c|c|}
\hline $\begin{array}{c}\text { Zeta potential } \\
(\mathrm{mV})\end{array}$ & $\begin{array}{c}\text { RMS roughness } \\
(\mathrm{nm})\end{array}$ & $\begin{array}{c}\text { Adhesion force (AdF) } \\
(\mathrm{nN})\end{array}$ & $\begin{array}{c}\text { Youngs' modulus }(E) \\
(\mathrm{MPa})\end{array}$ \\
\hline$-18 \pm 0.6$ & $3.44 \pm 0.7$ & $2.1 \pm 0.3$ & $46.7 \pm 5.8$ \\
\hline
\end{tabular}

Figure I AgNPs characterization.

Notes: (A) AFM, (B) HR-TEM, and (C) FE-SEM images of AgNPs; both low- and high-magnification images are shown in upper and lower panels, respectively, (D) UV-vis spectra, (E) RMS roughness graph, (F) XRD, (G) size distribution, and $(\mathbf{H})$ elemental analysis of AgNPs. Table summarizes the RMS roughness, $\zeta$ potential, adhesion force, and stiffness of the AgNPs. Data are presented as mean \pm standard deviation.

Abbreviations: AFM, atomic force microscopy; AgNPs, silver nanoparticles; EDXA, energy dispersive X-ray analysis; FE-SEM, field emission scanning electron microscopy; HR-TEM, high-resolution transmission electron microscopy; RMS, root mean square; UV-vis, UV-visible; XRD, X-ray powder diffraction.

that the moderate toxicity of AgNPs observed at high concentrations is due to their accumulation in the cytoplasmic membrane and the generation of free radicals that cause cell death. Previous report demonstrates that $\mathrm{Ag}^{+}$ions and the free radicals generated by AgNPs produce reactive oxygen species and induce oxidative stress. ${ }^{27}$ Also, they interact with disulfide or sulfhydryl groups, cause plasma membrane damage followed by rupture, and disrupt metabolic pathways, thereby contributing to cell death. ${ }^{27} \mathrm{We}$, therefore, measured total GSH and MDA levels as indicators of the oxidative stress induced by AgNPs. GSH depletion is a hallmark of apoptosis, Franco and Cidlowski summarized that GSH depletion is an early event during apoptosis, which occurs before the loss of cell viability. ${ }^{32}$ GSH depletion and posttranslational modifications of proteins through glutathionylation are critical regulators of apoptosis. ${ }^{32}$ Similarly, in our results, concentrationdependent decreases in the intracellular levels of total GSH were observed in all cell types after treatment with AgNPs (Figure 2D). The results show $\sim 1.5$-fold total GSH level reduction when compared with control group, which indicates apoptosis. However, at concentrations $<10 \mu \mathrm{g} / \mathrm{mL}$, AgNPs did not significantly deplete total GSH levels, suggesting that the toxicity is concentration dependent. There was an $\sim$ twofold increase in MDA levels in groups treated with $40 \mu \mathrm{g} / \mathrm{mL}$ AgNPs when compared with the control group (Figure 2E). Overall, AgNPs exhibited a dose-dependent reduction in GSH concomitant with an increased MDA level; this is due to the release of $\mathrm{Ag}^{+}$ions from AgNPs, which then induce significant intracellular oxidative stress. In turn, these events alter cellular activity and ultimately cause cell death. 
A

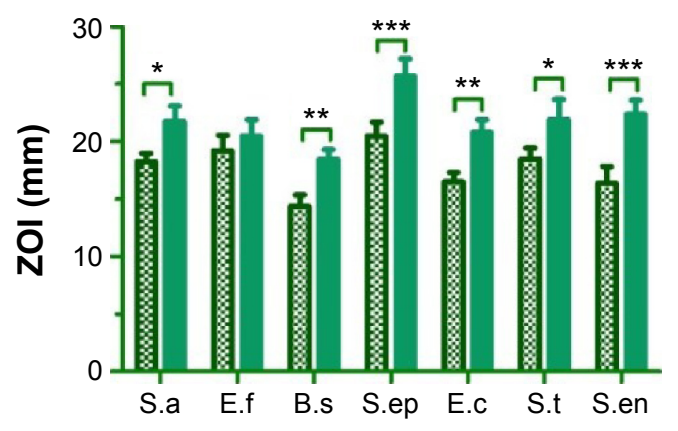

B

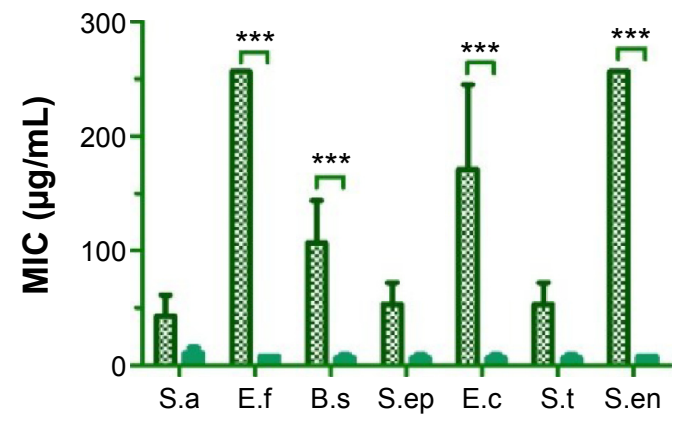

AgNPs Kanamycin
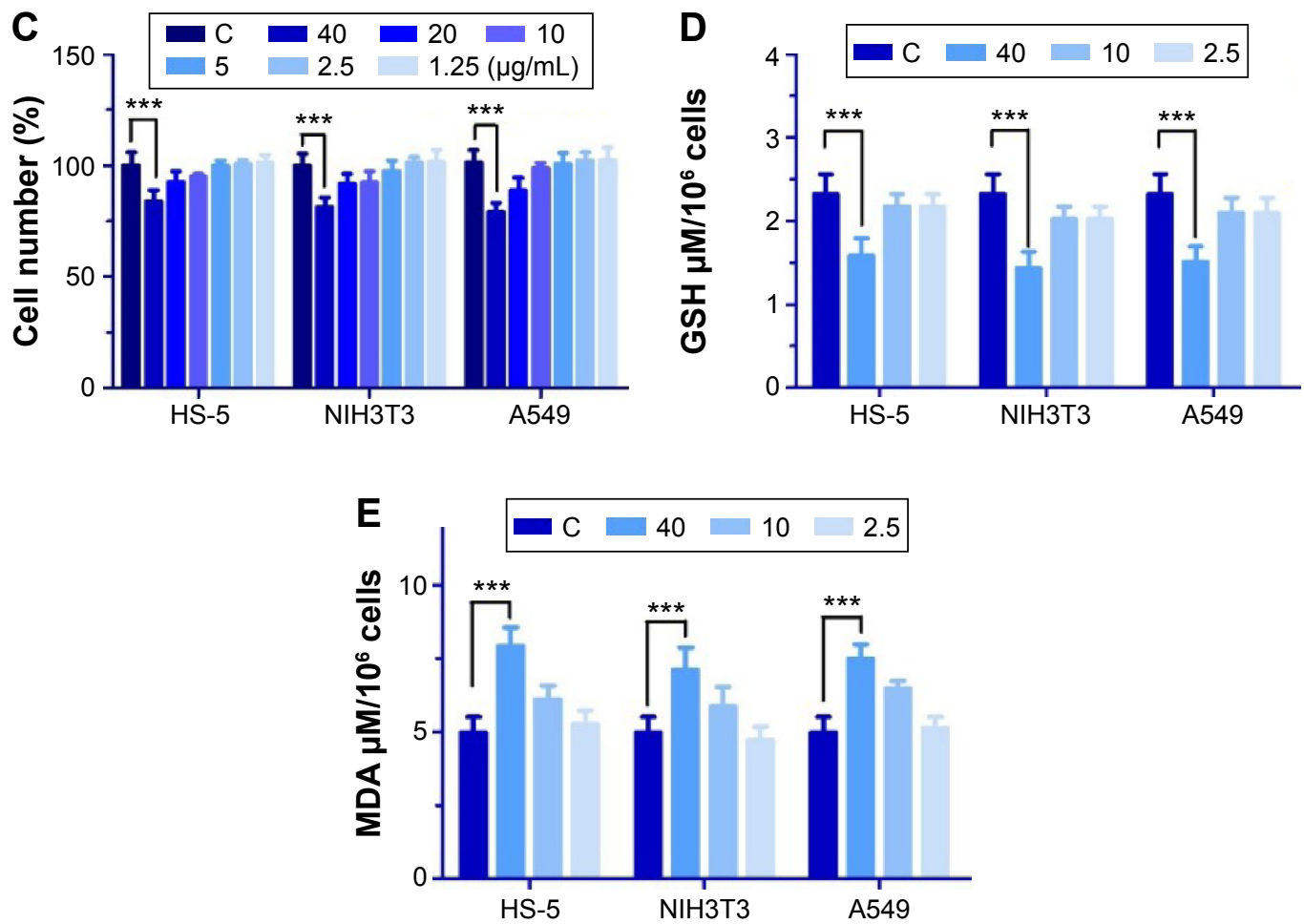

Figure 2 Antimicrobial and cytotoxicity assay.

Notes: (A) ZOI and (B) MIC by AgNPs and kanamycin against three Gram-negative and four Gram-positive bacterial strains. Results are mean \pm SD ( $\mathrm{n}=5$ ). Cytotoxicity of AgNPs in HS-5, NIH3T3, and A549 cells evaluated using the CCK-8 assay (C), GSH assay (D), and MDA assay (E), respectively. The color indicates the concentration of materials in the graphs. Experiments were repeated five times and significant differences between control and test samples are marked with $* P<0.05$, $* * P<0.01$, and $* * * P<0.00 \mathrm{I}$.

Abbreviations: AgNPs, silver nanoparticles; GSH, glutathione; MDA, malondialdehyde; MIC, minimum inhibitory concentration; ZOI, zones of inhibition; SD, standard deviation.

Early report demonstrates that AgNPs can become less toxic due to a strong non-specific binding of protein on the corona of NPs when incubated in the culture media, which alters their interaction with cells significantly. ${ }^{33}$ However, Shannahan et al reported that non-specific protein binding is less on functionalized-AgNPs with size of $20 \mathrm{~nm}$ than 110 $\mathrm{nm}$ due to the surface variation. ${ }^{34}$ Also demonstrated that the interaction of protein is weak and irreversible on bare AgNPs. On the other hand, the size-dependent effects of the AgNPs on cells and bacteria have been reported, for instance, Yuan et al described that ultrasmall (sub-2 $\mathrm{nm}$ range) $\mathrm{Ag}^{+}$species exhibited higher antimicrobial activities. ${ }^{35}$ Since, several reports have demonstrated the effects of various sizes of AgNPs and its capable bound ligand density on cytotoxicity and antimicrobial activity; we have narrowed down our focus on the effects of AgNPs on morphological, biophysical, and biomechanical properties of cells.

\section{Cell morphology and topography}

The morphology and topography of untreated HS-5, NIH3T3, A549 cells (control) and those treated with $40 \mu \mathrm{g} / \mathrm{mL}$ of AgNPs were evaluated by optical microscopy, SEM, and 
AFM, as shown in Figure 3. The cells were widespread, and potential candidates for AFM cell imaging were chosen using optical microscopy (Figure 3A-F). Following optical microscopy, no obvious changes were found in cell structure before and after treatment with AgNPs. In contrast to optical microscopy, SEM images revealed obvious changes in shape and structure following treatment with AgNPs. All cells had obtrusive filopodia, lamellipodia, and invadopodia, as confirmed by SEM imaging (Figure 3G-L). However, measurements of height, roughness, and cell-cell interactions were inconsistent and we concluded that SEM fails to provide any direct quantitative measurement. Hence, we utilized AFM to determine cellular properties such as height and roughness in response to AgNPs (Figures 3M-R and 4A), as this technique has been previously used in a similar context. The height images of control and AgNP-treated cells, obtained by AFM, provide a representative topography of the population. Figure 3M-R displays the 3D height images of control and AgNP-treated cells at $100 \times 100 \mu \mathrm{m}$ scale (Figure 3, third row; gold), at $50 \times 50 \mu \mathrm{m}$ (fourth row; blue) and $10 \times 10 \mu \mathrm{m}$ (fifth row; green), respectively. Morphological observation of the NP-treated cells compared with controls confirmed the changes in cell structure. The average height of cells varied among tested groups, and depended on the stretched and shrunken patterns of individual cell types. The average height of HS-5, NIH3T3, and A549 was $1.7 \mu \mathrm{m}, 1.5 \mu \mathrm{m}$, and $2.4 \mu \mathrm{m}$, respectively. However, the average height of cells increased to $2.25 \mu \mathrm{m}, 1.7 \mu \mathrm{m}$, and $2.7 \mu \mathrm{m}$ for HS-5, NIH3T3, and A549, respectively, after AgNPs treatment. We inferred that AgNPs interact at the cell surface and induce cell rounding that causes an increase in cell height (Figure 3). These images coincide well with SEM images of cells, in which AgNPs were visualized on the surface of cells (Figure 3H, J, $\mathrm{L}, \mathrm{N}, \mathrm{P}$, and R). The RMS roughness of the cell surface was a robust indicator of the properties of the cell surface before and after treatment with NPs (Figure 4A). Most importantly, AgNPs treatment increased the RMS roughness of cells, indicating that AgNPs were indeed adhering to the surface of cells

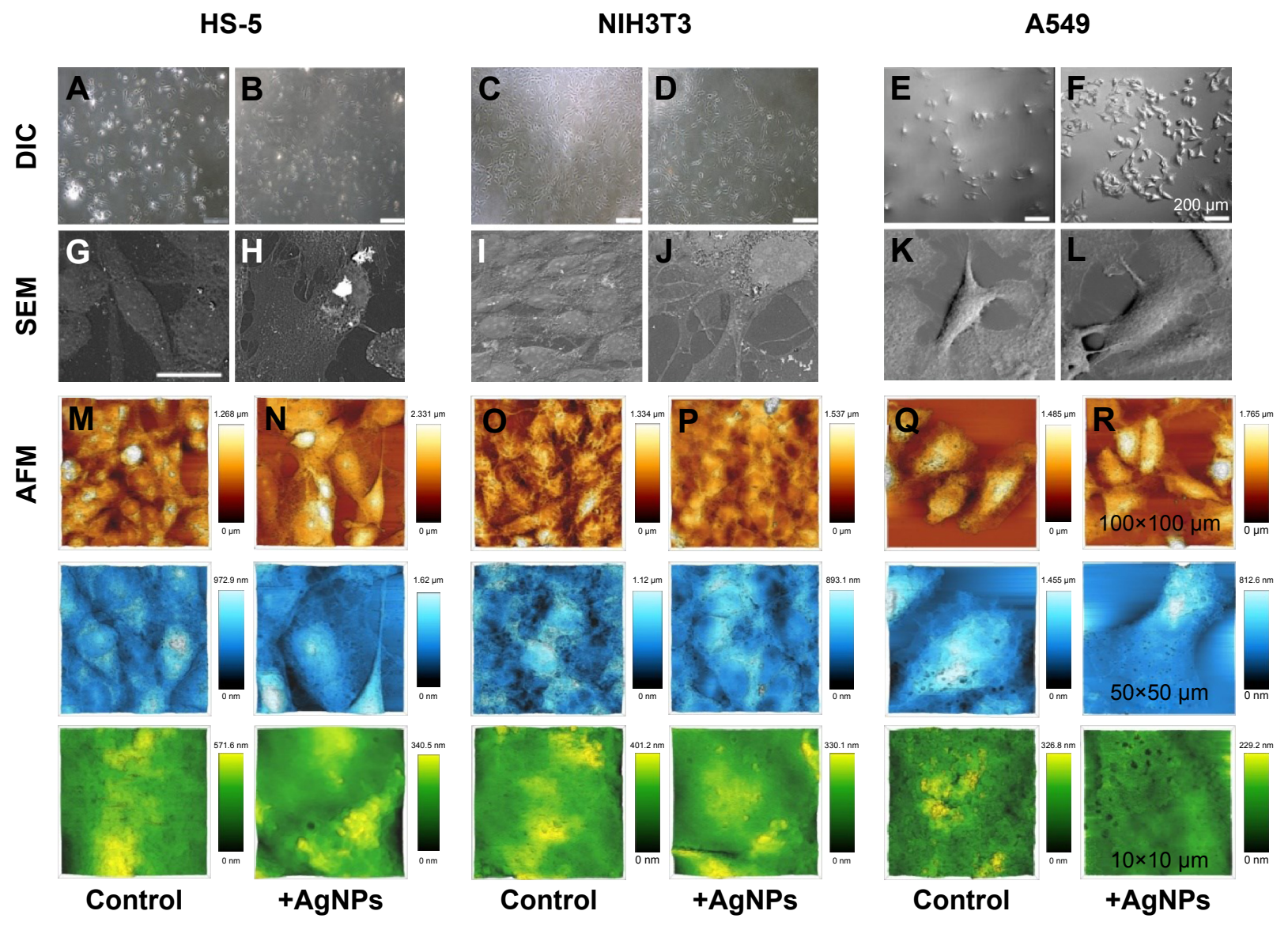

Figure 3 Morphology of cells treated with AgNPs.

Notes: Optical DIC (A-F), SEM (G-L), and 3D Bio-AFM (M-R) images of control and NP-treated HS-5, NIH3T3, and A549 cells. (M-R) Cells are scanned in an order of

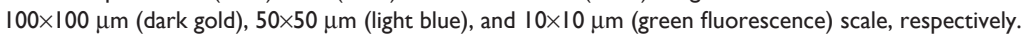

Abbreviations: AgNPs, silver nanoparticles; AFM, atomic force microscopy; DIC, differential interference contrast; NPs, nanoparticles; SEM, scanning electron microscopy. 

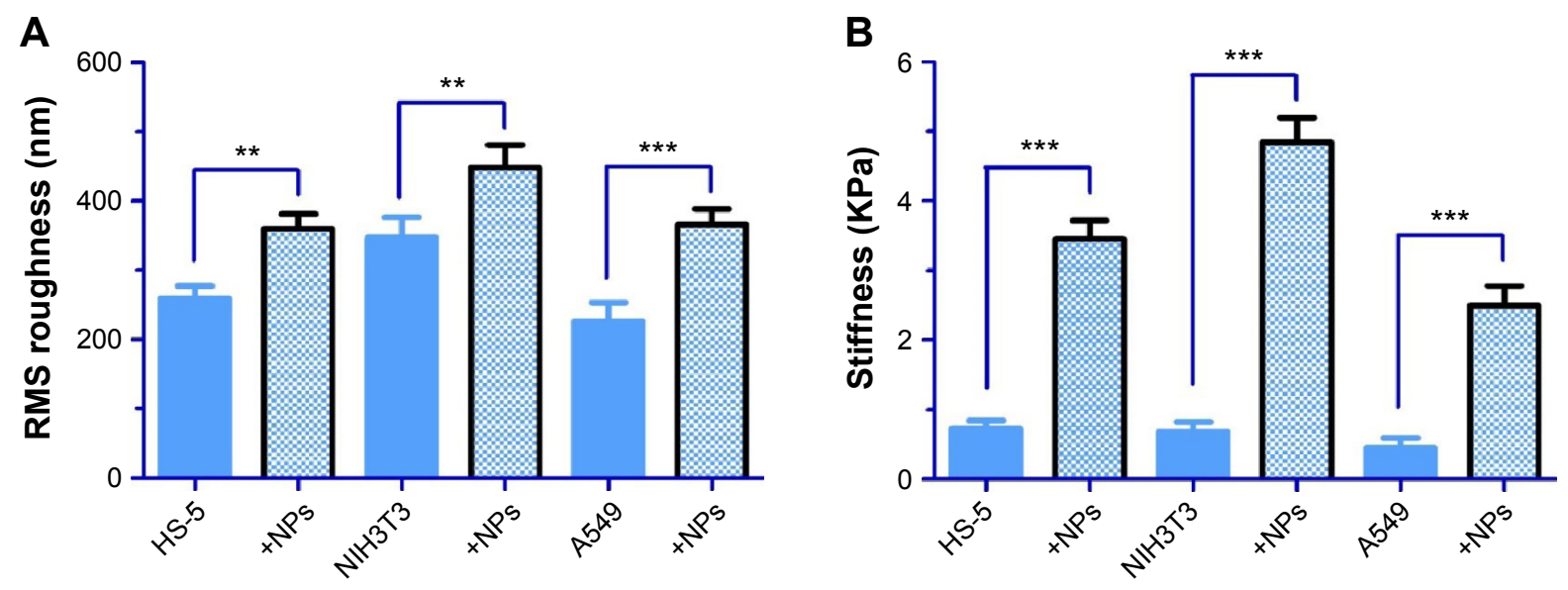

Figure 4 Biophysics and biomechanics of cells treated with materials.

Notes: Column graphs depict (A) RMS roughness and (B) stiffness measured in the control and AgNP-treated cells. Nanoindentation was performed in the perinuclear region of cells. Experiments were repeated five times and significant differences between control and test samples are marked with $* * P<0.0 \mathrm{I}$ and $* * * P<0.00 \mathrm{I}$.

Abbreviations: AgNPs, silver nanoparticles; NPs, nanoparticles; RMS, root mean square.

(Figure 4A). The roughness of control HS-5, NIH3T3, and A549 cells was $\sim 259 \mathrm{~nm}, \sim 347 \mathrm{~nm}$, and $\sim 227 \mathrm{~nm}$, whereas after AgNPs treatment this increased to $\sim 360 \mathrm{~nm}, \sim 448 \mathrm{~nm}$, and $\sim 365 \mathrm{~nm}$, respectively. We conclude that AgNPs alter the cell surface by adherence or internalization and thereby increase roughness. The size and charge of the AgNPs determine the way that they interact with cells. The interaction of AgNPs with cells was directly proportional to the surface roughness. Several studies have demonstrated that cell morphology is altered upon NPs treatment. For example, Pletikapic et al found that AgNPs interact with marine diatoms and cause local intracellular damage without disintegration of the cell wall. ${ }^{37}$ Similarly, Ogneva et al demonstrated that silica-based NPs directly interact with mesenchymal stem cell membranes, trigger a structural reorganization of cortical cytoskeleton, and cause morphological cellular changes ${ }^{16}$ Our data are consistent with those of these previous studies and indicate that AgNPs remain at the surface of cells or are internalized into the cytoplasmic membrane, but do not disrupt the cell membrane.

\section{Biophysics and biomechanics}

AFM-based nanoindentation is the most widely used tool to analyze the mechanical properties of nano/biomaterials and biological samples. Biophysical properties such as AdF and AtF of control and AgNP-treated cells were evaluated. These biophysical properties are mostly conferred by electrostatic, van der Waals, steric, and hydrophobic forces as well as the line tension between cell and aqueous medium, and the elastic and plastic properties of the cells. We speculated that interaction between AgNPs and cells would induce biophysical alterations in cells. FS was performed at a minimum of 30 different places on the specimen surface to measure the exerted AtF, and AdF between the tip and control or NP-treated cells. AFM probe jumps into contact the surface of the cells. Wherein, the nanoscale level force (AtF) is experienced between the tips and the cells while approaching the cells surface. The AtF of the AFM probe toward control HS-5, NIH3T3, and A549 cells (data not shown) was $\sim 0.47 \mathrm{nN}, \sim 0.62 \mathrm{nN}$, and $\sim 0.59 \mathrm{nN}$, respectively; this increased to $0.86 \mathrm{nN}, 0.97 \mathrm{nN}$, and 0.75 $\mathrm{nN}$ after NPs treatment. Likewise, the AdF for control HS-5, NIH3T3, and A549 cells $(\sim 42.2 \mathrm{nN}, \sim 57.2 \mathrm{nN}$, and $\sim 35.5 \mathrm{nN}$, respectively) increased to $63.4 \mathrm{nN}, 82.2 \mathrm{nN}$, and $49.3 \mathrm{nN}$, after treatment (data not shown). The variation in AtF and AdF values between the different control cell types might be due to different cellular structure and surface properties, such as components and molecular composition. In contrast, AgNP-treated cells displayed higher AdF and AtF values than those of control cells, changes in AdF and AtF values indicate possible internalization and interaction of AgNPs with cells. However, overall changes in AdF, AtF, and average cells height are not significantly different before and after AgNPs treatment and hence considered as ineffective to be applied as a biomarker. Then, we performed nanoindentation analysis of the perinuclear region of the cell surface by using $400 \mathrm{~nm}$ diameter spherical shape tips. The stiffness of cells before and after treatment with AgNPs was measured to understand the effect of the particles on biomechanical changes in cells. The average stiffness for control HS-5, NIH3T3, and A549 cells (Figure 4B) was $\sim 0.72 \mathrm{KPa}, \sim 0.68 \mathrm{KPa}$, and $\sim 0.45 \mathrm{KPa}$, respectively; this dramatically increased 

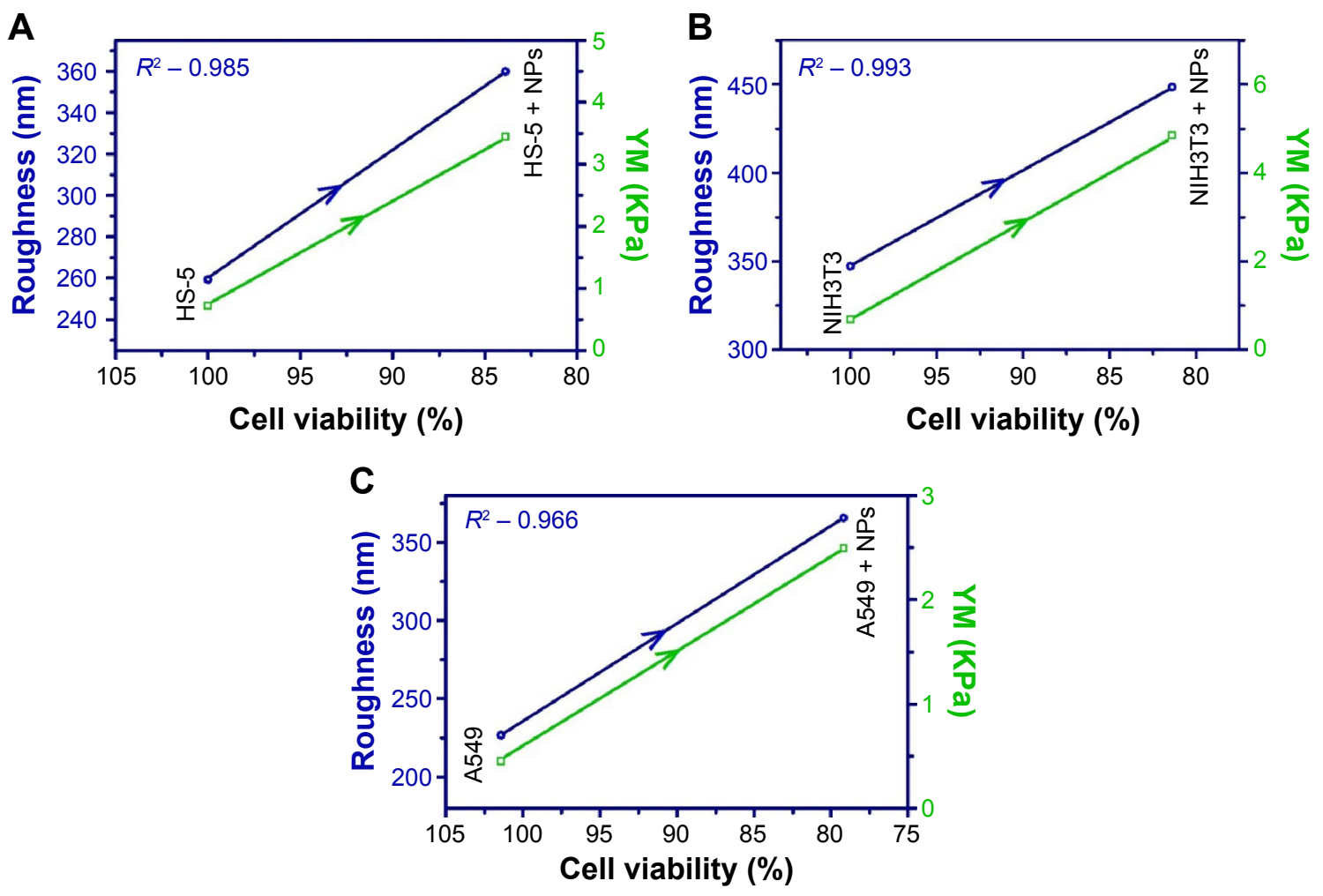

Figure 5 Correlation between the viability with roughness or stiffness.

Notes: Integration of roughness and stiffness (YM) with the viability of HS-5 (A), NIH3T3 (B), and A549 (C) cells before and after AgNPs treatment. Abbreviations: AgNPs, silver nanoparticles; NPs, nanoparticles; YM, Youngs' modulus.

to $\sim 3.45 \mathrm{KPa}, \sim 4.85 \mathrm{KPa}$, and $\sim 2.49 \mathrm{KPa}$ after treatment (Figure 4B). We infer that AgNPs either adhere strongly to the cell surface or translocate into the cells and thus generate mechanical tension/stress from cell membrane toward cytoplasm. Overall, our results show that cells experience various changes in their behavior and physicomechanical properties during NPs treatment and the associated toxic effects. The changes in stiffness and roughness are directly proportional to the concentration of AgNPs used (Figure 5). The correlation between the viability with roughness or stiffness of HS-5, NIH3T3, A549 cells (Figure 5A-C, respectively) before and after treatment with AgNPs was statistically significant $\left(R^{2}>0.9\right)$. The results depict an increase in roughness and stiffness with increasing toxicity. The increase in the cellular physicomechanical properties is due to deposition of AgNPs at the cell surface. In situ nanoscale resolution of NPs translocation or surface deposition and cell morphological properties (such as roughness and stiffness) is important for a wide range of studies including drug screening and cytopathology evaluation. Several studies have utilized AFM for the evaluation of cellular biomechanics. For instance, González-Cruz et al reported that the multi-lineage differentiation of stem cells is dependent on their stiffness. ${ }^{20}$ Similarly, stiffness has been used as a biomarker for the detection of dissected breast cancer tissue as reported by Plodinec et $\mathrm{al}^{21}$ and for the detection of osteoarthritis as reported by Stolz et al. ${ }^{23}$ In addition, osteogenic differentiation is associated with changes in cellular stiffness. ${ }^{28,38}$ As discussed earlier, Ogneva et al demonstrated that the stiffness of MSC increases upon their interaction with NPs due to the reorganization of the cytoskeleton. ${ }^{16}$ Our results are in agreement with the studies that demonstrate such altered cellular properties. We speculate that our findings could facilitate the investigation of cellular properties using AFM in order to screen for the effect of compounds with potential utility in the treatment of cancer, pulmonary, and critical infectious diseases. However, it should be noted that these results are insufficient in delivering a complete mechanism on physical/mechanical properties changes of cells upon NPs treatment and associated toxicity. Hence, it is encouraged that advanced study needs to focus more on mechanistic point of cells behavior changes correlated with NPs interaction and toxicity.

\section{Conclusion}

Size, surface potential, and surface properties of AgNPs are critical determinants of cell behavior and cytotoxicity. 
In HS-5, NIH3T3, and A549 cell lines, the AgNPs elicited dose-dependent toxicity. Optical microscopy and bio-AFM studies showed that AgNPs treatment considerably altered cell morphology, as indicated by their increased roughness. Also, stiffness of NP-treated cells significantly increased. These data suggest that the morphology, biophysical, and biomechanical properties of the cells are altered due to internalization or deposition of NPs. The changes are directly proportional to the interaction of the AgNPs with cells. These findings can be potentially applied to develop new biomarkers and to screen the in vitro efficacy of drugs for cancer treatment. Future studies based on the concepts introduced here will increase the understanding of the role of NPs with regard to cellular mechanics, subcellular distribution, and cellular responses in both normal and disease states.

\section{Acknowledgments}

This research was supported by the GRRC program of Gyeonggi province (2014-B03). This work was in part supported by the Nano-Material Technology Development Program through the National Research Foundation of Korea (NRF) (2011-0030233).

\section{Disclosure}

The authors report no conflicts of interest in this work.

\section{References}

1. Petros RA, DeSimone JM. Strategies in the design of nanoparticles for therapeutic applications. Nat Rev Drug Discov. 2010;9:615-627.

2. Doll TAPF, Raman S, Dey R, BurkhardP. Nanoscale assemblies and their biomedical applications. J R Soc Interface. 2013;10:20120740-20121254.

3. Subbiah R, Veerapandian M, Yun KS. Nanoparticles: functionalization and multifunctional applications in biomedical sciences. Curr Med Chem. 2010;17:4559-4577.

4. Tsuzuki T. Commercial scale production of inorganic nanoparticles. Int J Nanotechnol. 2009;6:567-578.

5. Behra R, Sigg L, Clift MJD, et al. Bioavailability of silver nanoparticles and ions: from a chemical and biochemical perspective. $J R S O C$ Interface. 2013;10:20130396-20130411.

6. Jiang S, Gnanasammandhan MK, Zhang Y. Optical imaging-guided cancer therapy with fluorescent nanoparticles. JR Soc Interface. 2010; 7:3-18.

7. Seaton A, Tran L, Aitken R, Donaldson K. Nanoparticles, human health hazard and regulation. $J R$ Soc Interface. 2010;7:S119-S129.

8. Nel A, Xia T, Mädler L, Li N. Toxic potential of materials at the nanolevel. Science. 2006;311:622-627.

9. Verma A, Stellacci F. Effect of surface properties on nanoparticle-cell interactions. Small. 2010;6:12-21.

10. Nel AE, Madler L, Velegol D, et al. Understanding biophysicochemical interactions at the nano-bio interface. Nat Mater. 2009;8: $543-557$.

11. Diaz B, Sanchez-Espinel C, Arruebo M, et al. Assessing methods for blood cell cytotoxic responses to inorganic nanoparticles and nanoparticle aggregates. Small. 2008;4:2025-2034.

12. Subbiah R, Ramasundaram S, Du P, et al. Evaluation of cytotoxicity, biophysics and biomechanics of cells treated with functionalized hybrid nanomaterials. J R Soc Interface. 2013;10:20130694-20130709.
13. Evans EA, Calderwood DA. Forces and bond dynamics in cell adhesion. Science. 2007;316:1148-1153.

14. AshaRani PV, Low Kah Mun G, Hande MP, Valiyaveettil S. Cytotoxicity and genotoxicity of silver nanoparticles in human cells. ACS Nano. 2009;3:279-290.

15. Lai Y, Chiang PC, Blom J, et al. Comparison of in vitro nanoparticles uptake in various cell lines and in vivo pulmonary cellular transport in intratracheally dosed rat model. Nanoscale Res Lett. 2008;3: 321-329.

16. Ogneva I, Buravkov S, Shubenkov A, Buravkova L. Mechanical characteristics of mesenchymal stem cells under impact of silica-based nanoparticles. Nanoscale Res Lett. 2014;9:284-294.

17. Andrea A, Paolo F. AFM: a versatile tool in biophysics. Meas Sci Technol. 2005;16:R65-R92.

18. Chaudhuri O, Parekh SH, Lam WA, Fletcher DA. Combined atomic force microscopy and side-view optical imaging for mechanical studies of cells. Nat Methods. 2009;6:383-387.

19. MacQueen L, Sun Y, Simmons CA. Mesenchymal stem cell mechanobiology and emerging experimental platforms. $J R$ Soc Interface. 2013;10:20130179-20130198.

20. González-Cruz RD, Fonseca VC, Darling EM. Cellular mechanical properties reflect the differentiation potential of adipose-derived mesenchymal stem cells. Proc Natl Acad Sci U S A. 2012;109:E1523-E1529.

21. Plodinec M, Loparic M, Monnier CA, et al. The nanomechanical signature of breast cancer. Nat Nano. 2012;7:757-765.

22. Longo G, Alonso Sarduy L, Rio LM, et al. Rapid detection of bacterial resistance to antibiotics using AFM cantilevers as nanomechanical sensors. Nat Nano. 2013;8:522-526.

23. Stolz M, Gottardi R, Raiteri R, et al. Early detection of aging cartilage and osteoarthritis in mice and patient samples using atomic force microscopy. Nat Nano. 2009;4:186-192.

24. Engler AJ, Sen S, Sweeney HL, Discher DE. Matrix Elasticity directs stem cell lineage specification. Cell. 2006;126:677-689.

25. Gilbert Y, Deghorain M, Wang L, et al. Single-molecule force spectroscopy and imaging of the vancomycin/d-Ala-d-Ala interaction. Nano Lett. 2007;7:796-801.

26. Carvalho FA, Connell S, Miltenberger-Miltenyi G, et al. Atomic force microscopy-based molecular recognition of a fibrinogen receptor on human erythrocytes. ACS Nano. 2010;4:4609-4620.

27. Subbiah R, Lee H, Veerapandian M, Sadhasivam S, Seo SW, Yun K. Structural and biological evaluation of a multifunctional SWCNTAgNPs-DNA/PVA bio-nanofilm. Anal Bioanal Chem. 2011;400: 547-560.

28. Subbiah R, Du P, Van SY, et al. Fibronectin-tethered graphene oxide as an artificial matrix for osteogenesis. Biomed Mater. 2014;9:065003.

29. Baker C, Pradhan A, Pakstis L, Pochan DJ, Shah SI. Synthesis and antibacterial properties of silver nanoparticles. J Nanosci Nanotechnol. 2005;5:244-249.

30. Cho KH, Park JE, Osaka T, Park SG. The study of antimicrobial activity and preservative effects of nanosilver ingredient. Electrochim Acta. 2005;51:956-960.

31. Morones JR, Elechiguerra JL, Camacho A, et al. The bactericidal effect of silver nanoparticles. Nanotechnology. 2005;16:2346-2353.

32. Franco R, Cidlowski JA. Apoptosis and glutathione: beyond an antioxidant. Cell Death Differ. 2009;16:1303-1314.

33. Saptarshi1 SR, Dusch A, Lopata AL. Interaction of nanoparticles with proteins: relation to bio-reactivity of the nanoparticle. JNanobiotechnol. 2013;11:26-38.

34. Shannahan JH, Lai X, Ke PC, Podila R, Brown JM, Witzmann FA. Silver nanoparticle protein corona composition in cell culture media. PLOS ONE. 2013;8:e74001-e74010.

35. Yuan X, Setyawati MI, Leong DT, Xie J. Ultrasmall Ag+-rich nanoclusters as highly efficient nanoreservoirs for bacterial killing. Nano Res. 2014;7:301-307.

36. Zheng K, Yuan X, Goswami N, Zhang Q, Xie J. Recent advances in the synthesis, characterization, and biomedical applications of ultrasmall thiolated silver nanoclusters. RSC Adv. 2014;4:60581-60596. 
37. Pletikapic G, Zutic V, Vinkovic Vrcek I, Svetlicic V. Atomic force microscopy characterization of silver nanoparticles interactions with marine diatom cells and extracellular polymeric substance. $J \mathrm{Mol}$ Recognit. 2012;25:309-317.
38. Titushkin I, Cho M. Modulation of cellular mechanics during osteogenic differentiation of human mesenchymal stem cells. Biophys $J$. 2007;93:3693-3702.

International Journal of Nanomedicine

\section{Publish your work in this journal}

The International Journal of Nanomedicine is an international, peerreviewed journal focusing on the application of nanotechnology in diagnostics, therapeutics, and drug delivery systems throughout the biomedical field. This journal is indexed on PubMed Central, MedLine, CAS, SciSearch $®$, Current Contents $® /$ Clinical Medicine,
Journal Citation Reports/Science Edition, EMBase, Scopus and the Elsevier Bibliographic databases. The manuscript management system is completely online and includes a very quick and fair peer-review system, which is all easy to use. Visit http://www.dovepress.com/ testimonials.php to read real quotes from published authors.

Submit your manuscript here: http://www.dovepress.com/international-journal-of-nanomedicine-journal 